\title{
The Great Beauty: Public Subsidies in the Italian Movie Industry
}

\author{
G. Meloni ${ }^{1,2} \cdot$ D. Paolini1 ${ }^{1,2,3} \cdot$ M. Pulina ${ }^{2,4}$
}

Received: 15 June 2015 / Accepted: 15 July 2015 / Published online: 24 July 2015

(C) Società Italiana degli Economisti (Italian Economic Association) 2015

\begin{abstract}
We examine the impact of public subsidies in the Italian movie industry by considering two dimensions: quantity (box-office revenues) and quality (film festival awards). Public subsidies and movie genres are employed as explanatory variables to investigate how public intervention and genre influence movie industry performance. We find that although public funding shows an overall negative influence on quantity and quality, there are some differences when considering public subsidies by genre. On balance, there is statistical evidence that dramas and thrillers are the genres that should be primarily financed by public agents.
\end{abstract}

Keywords Movie industry · Public subsidies · Awards · Box office

JEL Classification $\mathrm{Z} 18 \cdot \mathrm{C} 23$

\section{Introduction}

According to Art. 107 of the European Treaty, "Any aid granted by a Member State or through State resources in any form whatsoever which distorts or threatens to distort competition by favoring certain undertakings or the production of certain goods shall, in so far as it affects trade between Member States, be incompatible with the internal

\footnotetext{
$凶 \quad$ D. Paolini dpaolini@uniss.it

1 DiSea, University of Sassari, Sassari, Italy

2 CRENoS, Cagliari, Italy

3 CORE, Louvain-la-Neuve, Belgium

4 POLCOMING, University of Sassari, Sassari, Italy
} 
market". A notable exception is public aid for movies, which is permitted for cultural goals, that is, to promote culture and heritage conservation where such aid does not affect trading conditions and competition in the Union to the extent that is contrary to the common interest.

If we consider the main European countries in terms of movie production, we find that direct subsidies from government agencies are an important source of film financing. In 2012, the governments of Germany, France, Italy and the UK provided financing in the amounts of 201.3, 720.1, 75.8 and 134.2 million euros, respectively. Moreover, film productions can receive indirect subsidies in the form of tax shelters for investors, valued in 2011 at 222 million euros for the UK, 90 for Italy, and 100 for France. ${ }^{1}$

From the perspective of the public, several explanations that may support public intervention in the movie industry can be identified. First, movies can be viewed as merit goods for which there is often no demand from the public. In this respect, a subsidy may increase the revenue received but also decrease the costs for producers, who may be encouraged to become more efficient and to produce at a more socially oriented level. Second, public intervention is desirable in the presence of positive externalities. Movies often play an important role in aiding the educational development of schoolchildren by strengthening their critical skills and allowing them to witness dramatic historical episodes. Informational and documentary movies can also be important for lifelong learning in adulthood. Third, public subsidies for the movie industry are likely to enhance social and cultural benefits that range from regeneration, social inclusion and an affirmation of national identity (see also Pratt 2005). In this sense, evaluating public interventions in cultural products is not a simple task.

In Italy, legislation concerning economic and financial support by the public for various forms of cultural activities, such as music and theatre, was issued with Law 163 on the April 30, 1985, which represented the "new discipline of interventions in favor of the performing arts" and $25 \%$ delineated the total funds to be granted to the movie industry. A further regulation on motion pictures was issued in 2004 that established that public funding could be allocated either directly to the production of a new movie or indirectly by subsiding movies or authors based on their quality as defined by a set of criteria. In addition, another type of contribution can be allocated to movie producers and authors based on box-office performance (see Forte and Mantovani 2013 for a more detailed discussion).

In this paper, we consider Italian movies released in the domestic market between 2002 and $2011 .^{2}$ The aim is to provide an investigation of the impact of public subsidies on box-office revenues and to control for their possible impact on the quality of financed movies as well as for genre heterogeneity. On the one hand, a fixed effects and random effects panel data analysis is pursued to investigate the impact of public subsidies on box-office revenues. On the other hand, a panel Poisson is employed to investigate to

\footnotetext{
1 See Lange (2012).

2 We focus on the domestic market only, because of all the movies in our sample, only a small amount received an international distribution. This is coherent with the shrink of market share for Italian movies highlighted in Waterman and Jayakar (2000).
} 
what extent public subsidies and genre influence the number of prizes won, which can be regarded as a proxy of implicit quality in the Italian movie industry.

The paper is organized as follows. Section 2 presents the related literature, while Sect. 3 highlights the methodological framework. In Sect. 4, the case study is presented, and a description of the data is provided. The empirical findings that emerge from the empirical investigation are reported in Sect. 5. Concluding remarks are presented in the last section.

\section{Related Literature}

Movie industry has attracted research attention from economics and marketing scholars, due to its economic relevance and complex characteristics. In particular, high production costs and uncertainty of demand (De Vany 2004; Ebbers and Wijnberg 2012; Fernandez-Blanco et al. 2014), timing strategies and seasonality issues (Einav 2007, 2010; Chiou 2008; Belleflamme and Paolini 2015).

Holbrook and Addis (2008), implementing a two-path model of motion-picture success, claim that market performance and artistic excellence, measured by industry recognition (i.e Oscars and other awards), are uncorrelated aspects of movie success. Several papers have estimated the impact of critical reviews (Eliashberg and Shugan 1997; Basuroy and Ravid 2014 among the others) and awards (Lee 2009) on movie revenues, but none of them consider these types of variables to evaluate the quality of cultural products.

Bagella and Becchetti (1999) work is one of the first and one of the few studies that investigates some critical issues within the Italian movie industry over the period between 1985 and 1996 using a sample of 977 Italian films. Using a Generalized Method of Moments Heteroskedasticity and Autocorrelation Consistent (GMM-HAC) approach, the authors find that public subsidies do not influence total admissions, daily revenues or per screen daily admissions. In addition, the positive and statistically significant effect of the comedy genre on total admissions shows that the decision to produce films in this genre has an independent, positive effect on box-office revenues regardless of ex ante cast and director popularity. Along the same line, McKenzie and Walls (2012), for the case of Australia, find that government subsidies have no impact on a film's financial success at the box office. Jansen (2005) examines the case of the movie industry in Germany and finds that public subsidies tend to support producers who have consistently had above-average success in their movie performance. Hence, this finding stands in contrast with the author's prior belief that public funding tends to distort producers' incentives to make movies that match viewers' expectations.

To sum up, despite a large body of literature in the field-see McKenzie and Walls (2012) and Chisholm et al. (2015) for a detailed survey-only a few papers consider how public intervention affects box office performance and, to the best of our knowledge, this article is the first to analyze its impact on quality.

\section{Methodological Framework}

The first step of the empirical investigation is based on an analysis of the box-office performance of the movie industry within the Italian domestic market. The baseline 
specification consists of a movie's revenue $i$ as a function of public subsidies and genre, that is, comedy, drama, or thriller, with documentary treated as the reference category. The continuous variables are expressed in logarithm terms and are adjusted for inflation. The model is specified as follows:

${\text { ln } \text { revenue }_{i}=\beta_{0}+\beta_{1} \text { ln subsidies }}_{i}+\beta_{2}$ comed $_{i}+\beta_{3}$ drama $_{i}+\beta_{4}$ thriller $_{i}+\varepsilon_{i}$

where $\beta_{r}$ for $r=[1,4]$ are the parameters of the model and $\varepsilon_{i}$ is the error term. A standard panel data approach is followed by grouping the observations by year and comparing the results obtained from running a random and a fixed effects model. The random effects assumption is that the individual specific effects are uncorrelated with the independent variables, while the fixed effect assumption is that the individual specific effects are correlated with the independent variables. The Hausman test is run to empirically discriminate between the two models.

The next step in the investigation is to evaluate the impact of public financing for different types of movies, that is, to assess the iteration between genres and subsidies, with the latter expressed in logarithm and real terms. Thus, the following specification is considered:

$$
\text { ln revenue }_{i}=\beta_{0}+\Delta^{\prime} \text { subsidized genres }_{i}+\Gamma^{\prime} \text { non subsidized genres }_{i}+\varepsilon_{i}
$$

where subsidized genres is a vector of iteration variables between the four genres and public subsidies; non-subsidized genres is a vector of interaction dummy variables that takes the value 1 if a movie belongs to a given genre and has not received public funding. $\Delta$ and $\Gamma$ are the parameters of the model, and $\varepsilon$ is the error term. As for the baseline specification, panel random and fixed effects models are run, and the Hausman test is used to empirically discriminate between the two approaches.

Once we can establish to what extent public intervention affects box-office revenues, as a further step in the investigation, the impact of public subsidies on the Italian movie industry is assessed in terms of the quality of the financed movies. Thus, the number of awards won is employed as the dependent variable. This variable is a count variable; hence, a panel Poisson model must be estimated, where the assumption that the variance is equal to the mean holds. As a robustness check, this hypothesis is further tested against a panel negative binomial model through a likelihood ratio test. The baseline model is specified as follows:

$$
\begin{aligned}
\text { award }_{i}= & \beta_{0}+\beta_{1} \text { festival }_{i}+\beta_{2} \text { ln } \text { subsidies }_{i}+\beta_{3} \text { comed }_{i}+\beta_{4} \text { drama }_{i} \\
& +\beta_{5} \text { thriller }_{i}+\varepsilon_{i}
\end{aligned}
$$

where awards for the ith movie are a function of participation at festivals, subsidies, if any, and genres. $\beta_{r}$ for $r=[1,5]$ are the parameters to be estimated, and $\varepsilon$ is an error term. As a further extension of the model, the iteration between subsidies and genres is also considered as follows: 
Table 1 Movies' descriptive statistics

\begin{tabular}{|c|c|c|c|c|}
\hline Variable & Mean & Std. deviation & Min & $\operatorname{Max}$ \\
\hline \multicolumn{5}{|l|}{ Whole sample } \\
\hline Subsidies (adjusted) & 636,898 & $1,011,733$ & 0 & $4,200,919$ \\
\hline \multicolumn{5}{|l|}{ Genres } \\
\hline Drama & 0.448 & & 0 & 1 \\
\hline Comedy & 0.435 & & 0 & 1 \\
\hline Documentary & 0.059 & & 0 & 1 \\
\hline Thriller & 0.058 & & 0 & 1 \\
\hline Observations & 754 & & & \\
\hline \multicolumn{5}{|l|}{ Subsidized movies } \\
\hline \multicolumn{5}{|l|}{ Genres } \\
\hline Drama & 0.534 & & 0 & 1 \\
\hline Comedy & 0.334 & & 0 & 1 \\
\hline Documentary & 0.061 & & 0 & 1 \\
\hline Thriller & 0.071 & & 0 & 1 \\
\hline Festivals & 25.70 & 27.96 & 0 & 139 \\
\hline Awards & 5.57 & 9.16 & 0 & 51 \\
\hline Observations & 311 & & & \\
\hline \multicolumn{5}{|l|}{ Data on festivals } \\
\hline Festivals & 22.69 & 25.56 & 0 & 139 \\
\hline Awards & 4.94 & 8.16 & 0 & 51 \\
\hline Observations & 529 & & & \\
\hline
\end{tabular}

$$
\begin{aligned}
\text { awards }_{i}= & \beta_{0}+\beta_{1} \text { festival }_{i}+\Delta^{\prime} \text { subsidized genres }_{i} \\
& +\Gamma^{\prime} \text { non subsidized genres } s_{i}+\varepsilon_{i}
\end{aligned}
$$

where the subsidized genres and non-subsidized genres vectors are defined as in Eq. 4. $\Delta$ e $\Gamma$ are the parameters of the model, and $\varepsilon$ is the error term.

\section{Data}

To test the previous hypotheses, panel data for 754 Italian movies exhibited during the 2002-2011 period are employed. The dependent variable, as expressed in Eqs. 1 and 2 , is box-office revenue (expressed in euros and adjusted for inflation, base year 2011), which is obtained for each movie and genre from several sources. ${ }^{3}$ Public subsidies, which are used as an explanatory variable, are obtained from MiBACT (Ministero dei Beni e delle Attività? Culturali e del Turismo). awards won at film festivals, which are used as the dependent variable in Eqs. 3 and 4, are collected from www.cinemaitaliano. info. Table 1 presents descriptive statistics for the whole sample.

\footnotetext{
3 In particular, http://www.imdb.com, http://www.boxeofficemojo.com, http://www.comingsoon.it.
} 
The sample shows a strong predominance of dramas and comedies overthrillers and documentaries, with the former accounting for $45 \%$ of the sample and the latter $43 \%$. Notably, 311 of a total of 754 movies were granted public subsidies from MiBACT. Over the time span under analysis, the average public financing per movie was 636 thousand euros, with a maximum of 4.2 million. When considering the sub-sample of financed movies, dramas account for $53 \%$ of the total public financing, while comedies account for $33 \%$. This difference in the allocation of public resources can be explained by multiple factors: first, comedies are less likely to contain cultural aspects of public interest; second, as shown by Bagella and Becchetti (1999), Italian movie viewers exhibit a strong preference for comedies; thus, box-office revenues for such movies are above the mean, and production companies are less likely to seek for public financing. For a subsample of 461 movies, information on participation at film festivals and awards won are available; 279 of these movies received a public subsidy, which accounts for $90 \%$ of the subsidized movies sample. Tables 2 and 3 highlight some interesting features regarding the statistical distribution of the variables.

On average, each movie in the subsample competed in 26 festivals, winning 5.67 awards. These values slightly increase for publicly financed movies to 28.64 festivals and 6.21 awards. However, for both groups, there is a predominance of zero awards associated with a rather low median value (that is, the median is equal to 2 for the whole subset, and the median is equal to 3 for subsidized movies). Moreover, the analysis of the percentiles shows that the distribution of the awards is heavily skewed toward the right, which implies that only a small number of movies obtained the majority of the awards. The third column of Tables 2 and 3 shows the ratio between awards won and festival participation. While a simple correlation analysis of the two variables indicates strong reciprocity (0.8), the mean and median values are approximately 16$19 \%$, respectively; hence, frequent participation at festivals does not automatically lead to more awards.

Table 2 Festivals and awards

\begin{tabular}{lclllll}
\hline & Festivals & \multicolumn{3}{c}{ Awards } & Win ratio \\
\hline & & Smallest & & Smallest & & Smallest \\
$1 \%$ & 1 & 1 & 0 & 0 & 0 & 0 \\
$5 \%$ & 2 & 1 & 0 & 0 & 0 & 0 \\
$10 \%$ & 3 & 1 & 0 & 0 & 0 & 0 \\
$25 \%$ & 8 & 1 & 1 & 0 & 0.04 & 0 \\
$50 \%$ & 18 & & 2 & & 0.16 & \\
& & Largest & & Largest & & Largest \\
$75 \%$ & 35 & 125 & 7 & 44 & 0.27 & 1 \\
$90 \%$ & 61 & 128 & 15 & 44 & 0.42 & 1 \\
$95 \%$ & 129 & 130 & 22 & 50 & 0.50 & 1 \\
$99 \%$ & & 26.03 & 40 & 51 & 1 & 1 \\
Mean & & 25.73 & & 5.67 & & 0.19 \\
Std deviation & 461 & & & 8.50 & & 0.22 \\
Observations & & & & & \\
\hline
\end{tabular}


Table 3 Festivals and awards: subsidized movies

\begin{tabular}{lllllll}
\hline & Festivals & \multicolumn{3}{c}{ Awards } & Win ratio \\
\hline & & Smallest & & Smallest & & Smallest \\
$1 \%$ & 1 & 1 & 0 & 0 & 0 & 0 \\
$5 \%$ & 2 & 1 & 0 & 0 & 0 & 0 \\
$10 \%$ & 4 & 1 & 0 & 0 & 0 & 0 \\
$25 \%$ & 9 & 1 & 1 & 0 & 0.05 & 0 \\
& & Largest & & Largest & & Largest \\
$75 \%$ & 39 & 125 & 7 & 44 & 0.25 & 1 \\
$90 \%$ & 72 & 128 & 16 & 44 & 0.40 & 1 \\
$95 \%$ & 92 & 130 & 33 & 50 & 0.47 & 1 \\
$99 \%$ & 128 & 139 & 44 & 51 & 1 & 1 \\
Mean & & 28.64 & & 6.21 & & 0.19 \\
Std deviation & & 28.05 & & 9.46 & & 0.23 \\
Observations & 279 & & & & & \\
\hline
\end{tabular}

\section{Results}

The hypotheses regarding the performance of the Italian movie industry are based on two dimensions: quantity (i.e., box-office revenue) and quality (i.e., prizes won at film festivals). For the analysis of box-office performance, the baseline specification expresses the revenue of a movie $i$ as a function of public subsidies, if any, and genre, that is, comedy, drama, thriller or documentary, which is treated as the reference category (see Equation ). As stated in the methodological section, two separate specifications are run, that is, a panel random effects model and a panel fixed effects model. To establish which model empirically fits the data better, a Hausman test is run. In this case, the calculated value of the Chi-squared $=21.48(0.000)$ implies that the fixed effects model under the alternative hypothesis is empirically a better specification that presents a higher level of efficiency. Table 4 presents the relevant results obtained from each of the specifications.

Overall, the results are rather congruent in terms of magnitude of the coefficients and in terms of sign in both the random and fixed effects specifications. The first result is that publicly subsided movies, when compared with non-subsided movies, have a negative impact on box-office revenue. Furthermore, comedies appear to play a leading role in attracting demand, followed by thrillers and dramas, when compared with the reference category. These findings are all consistent with the results obtained by Bagella and Becchetti (1999), thus reinforcing the relevant role played by the comedy genre in driving the box-office performance of Italian movies as well as the negative effects exerted by public intervention.

As a further expansion of the investigation, the impact of public financing, if any, for different movie genres on box-office revenues is investigated, as expressed in Eq. 2. Once again, a panel random model and a fixed effects model are run. The Hausman test implies that the fixed effects model presents a higher level of efficiency. 
Table 4 Italian movie revenues: base specification

\begin{tabular}{lll}
\hline & Fixed effects & Random effects \\
\hline In subsidies & $-0.0352^{* *}(-2.95)$ & $-0.0676^{* * *}(-4.96)$ \\
Drama & $1.145^{* *}(3.22)$ & $1.146^{* *}(3.24)$ \\
Comedy & $2.490^{* * *}(6.99)$ & $2.484^{* * *}(7.05)$ \\
Thriller & $1.361^{* *}(2.88)$ & $1.319^{* *}(2.81)$ \\
Documentary & (Omitted) & $($ Omitted $)$ \\
$R^{2}$ & & \\
Within & 0.149 & 0.143 \\
Between & 0.308 & 0.303 \\
Overall & 0.119 & 0.125 \\
$\mathrm{~N}$ & 754 & 754 \\
\hline
\end{tabular}

$t$ statistics in parentheses

$* p<0.05$; ** $p<0.01$; *** $p<0.001$

Table 5 Italian movie revenues: budget iteration with genres

\begin{tabular}{lll}
\hline & Fixed effects & Random effects \\
\hline Subs comedy & $0.439^{* *}(2.63)$ & $0.442^{*}(2.57)$ \\
Nosubs comedy & $7.540^{* *}(3.29)$ & $7.822^{* *}(3.30)$ \\
Subs drama & $0.388^{*}(2.41)$ & $0.392^{*}(2.35)$ \\
Nosubs drama & $5.699^{*}(2.48)$ & $5.991^{*}(2.53)$ \\
Subs thriller & $0.413^{*}(2.48)$ & $0.412^{*}(2.39)$ \\
Nosubs thriller & $5.837^{*}(2.51)$ & $6.105^{*}(2.55)$ \\
Subs documentary & $0.305(1.73)$ & $0.308(1.69)$ \\
Nosubs documentary & $4.891 *(2.11)$ & $5.157 *(2.16)$ \\
$R^{2}$ & & \\
Within & 0.173 & 0.172 \\
Between & 0.210 & 0.187 \\
Overall & 0.144 & 0.148 \\
N & 754 & 754 \\
\hline
\end{tabular}

Table 5 shows evidence of a positive and statistically significant impact of subsidies for three genres out of four. However, the magnitude of the interaction coefficients of non-financed movies is much higher, which highlights their greater impact on revenues. On the whole, financing comedies guarantees the best resource allocation, which again confirms the results of Bagella and Becchetti (1999). Nevertheless, the preference of Italian viewers for the comedy genre suggests further policy implications. The empirical results in fact suggest that there should be a shift in public resource allocations toward thrillers and dramas, which are also likely to exert positive externalities and to play a greater educational role.

Turning to the factors that influence the quality of the produced movies, Eq. 3 is estimated employing a Poisson specification. Both the coefficients and the incidence 
Table 6 Poisson model for awards

\begin{tabular}{lll}
\hline & Coefficients & Incidence ratio \\
\hline Festivals & $0.0283 * * *(55.48)$ & 1.02 \\
ln subsidies & $-0.0152 * * *(-4.84)$ & 0.98 \\
Comedy & $0.656 * * *(6.30)$ & 1.93 \\
Drama & $0.868 * * *(8.57)$ & 2.38 \\
Thriller & $0.731 * * *(5.23)$ & 2.08 \\
Documentary & & $($ Omitted $)$ \\
N & & 461 \\
Pseudo $R^{2}$ & & 0.524 \\
\hline
\end{tabular}

rate ratios are presented. The latter measure is used to compare the incidence rates of events occurring at any given point in time or space. From the descriptive statistics, it emerges that 279 of the 311 financed movies participated in at least one festival (see Table 3). Hence, by takinginto account only film festival participation and prizes won, a subset of 461 movies is considered. As a matter of interest, the Poisson results are congruent with the results obtained when employing a negative binomial specification (full results are available upon request). The regression results from the baseline model are presented in Table 6.

The magnitude of the incidence ratio for the festival participation variable confirms that participation at festivals does not automatically lead to more awards. Moreover, as in the previous baseline model, public subsidies show a negative and statistically significant coefficient sign, and the IRR shows that awards are expected to decrease by a factor of 0.98 when holding all other variables in the model constant. Moreover, the genre with the best performance is drama; this result is coherent with the belief that quality may be better perceived in movies with an insightful and dramatic characterization. Proceeding a step further into the specification, Eq. 4 is estimated, and the interaction variables (i.e., subsidies, non-subsidies and different genres) are included in the Poisson specification.

Table 7 shows that the impact of subsidies on quality for each of the genres is rather negligible when compared with non-subsidies. Finally, the incidence rate ratios indicate that subsidized thrillers and dramas are the types of movies that lead to a relatively higher performance in terms of quality and therefore should also be also supported more by the public.

Moreover, we consider the possible impact of the added regulation from 2004 on box-office revenues and the quality of subsidized movies. We implement a dummy variable that takes the value 1 for movies released 2 years after the introduction of the change in the law. A 2-year lag is coherent with the average production time for a full-length motion picture and allows us to split the sample to consider a pre-treatment period so we can identify a possible shock in the dependent variables. However, we find that there is no statistical significance after the introduction of the reform in both box-office performance and awards granted. 
Table 7 Poisson model for awards: budget iteration with genres

$t$ statistics in parentheses

$* p<0.10$; ** $p<0.05$;

$* * * p<0.01$

\begin{tabular}{lll}
\hline & Coefficients & $\begin{array}{l}\text { Incidence } \\
\text { ratio }\end{array}$ \\
\hline Festivals & $0.0284^{* * *}(53.31)$ & 1.03 \\
Nosubs comedy & $0.898^{*}(1.72)$ & 2.45 \\
Subs comedy & $0.0645^{*}(1.69)$ & 1.06 \\
Nosubs drama & $1.316^{* *}(2.54)$ & 3.72 \\
Subs drama & $0.0684^{*}(1.89)$ & 1.07 \\
Nosubs thriller & $0.598(1.06)$ & 1.81 \\
Subs thriller & $0.0758^{* *}(1.99)$ & 1.08 \\
Nosubs documentary & $0.547(1.02)$ & 1.73 \\
Subs documentary & $0.000470(0.01)$ & 1.00 \\
$\mathrm{~N}$ & & 461 \\
Pseudo $R^{2}$ & & 0.530 \\
\hline
\end{tabular}

\section{Conclusions}

The primary aim of this paper has been to analyze the impact of public subsidies on the Italian movie industry by employing panel data from 2002 to 2011. In our analysis, we have considered two main indicators as dependent variables, quantity expressed by revenues and quality in terms of prizes won at film festivals. We have shown that public funding (compared with non-subsidized movies) yields a negative influence on performance and quality. This result is in line with that of McKenzie and Walls (2012) for the Australian market and Bagella and Becchetti (1999) for the Italian movie industry, yet there are some differences when considering public subsidies by genre. We show that there is evidence of a positive and statistically significant impact of subsidies for three out of four genres, although the non-financed movies have a larger effect on performance. If we consider the impact of subsidies on quality for each of the genres, we have found that publicly subsidized movies have a positive but a rather negligible impact. Only thrillers and dramas have a relatively higher performance, as suggested by our analysis. In particular, our analysis suggests that public resources should be dedicated to enhancing dramas and thrillers rather than comedies. In fact, the latter genre tends to outperform the other types of movies both in terms of quantity and quality despite support from the public because it is the most preferred genre by Italian consumers.

\section{References}

Bagella M, Becchetti L (1999) The determinants of motion picture box-office performance: evidence from motion pictures produced in Italy. J Cult Econ 23:237-256

Basuroy S, Ravid SA (2014) How relevant are experts in the internet age? Evidence from the motion pictures industry. Working Paper, University of Oklahoma

Belleflamme P, Paolini D (2015) Strategic promotion and release decisions for cultural goods. mimeo, CORE 
Chiou L (2008) The timing of movie releases: evidence from the home video industry. Int J Ind Organ 26(5):1059-1073

Chisholm DC, Fernandez-Blanco V, Ravid SA, Walls WD (2015) Economics of motion pictures: the state of the art. J Cult Econ 39:1-13

De Vany A (2004) Hollywood economics: how extreme uncertainty shapes the film industry. Routledge, London

Ebbers JJ, Wijnberg NM (2012) The effects of having more than one good reputation on distributor investments in the film industry. J Cult Econ 36:227-248

Einav L (2007) Seasonality in the U.S. motion picture industry. Rand J Econ 38:127-145

Einav L (2010) Not all rivals look alike: estimating an equilibrium model of the release date timing game. Econ Inq 48:369-390

Eliashberg J, Shugan SM (1997) Film critics: influencers or predictors? J Mark 61(2):68-78

Fernandez-Blanco V, Ginsburgh V, Prieto-Rodríguez J, Weyers S (2014) As good as it gets? Blockbusters and the inequality of box office results since 1950. In: Kaufman J, Simonton D (eds) The social science of the cinema, Oxford University Press, Oxford, pp 269-285

Forte F, Mantovani M (2013) On conventional sources on financing movies: the case of Italy. 54th annual conference Alma Mater Studiorum, University of Bologna, Department of Economics, 24-26 October

Holbrook MB, Addis M (2008) Art versus commerce in the movie industry: a two-path model of motionpicture success. J Cult Econ 32:87-107

Jansen C (2005) The performance of German motion pictures, profits and subsidies: some empirical evidence. J Cult Econ 29(3):191-212

Lange A (2012) Film market trends and film funding in four selected European Countries. European Audiovisual Observatory, Council of Europe, Brussels

Lee FLF (2009) Cultural discount of cinematic achievement: the academy awards and U.S. movies' East Asian box office. J Cult Econ 33:239-263

McKenzie J, Walls WD (2012) Australian films at the Australian box-office: performance, distribution, and subsidies. J Cult Econ 37(2):247-269

Pratt AC (2005) Cultural industries and public policy. Int J Cult Policy 11(1):31-44

Waterman D, Jayakar KP (2000) The competitive balance of the Italian and American film industries. Eur J Commun 15(4):501-528 